\title{
Pharmacological evaluation of tacrolimus (FK-506) on ischemia reperfusion induced vasculatic neuropathic pain in rats
}

\author{
Arunachalam Muthuraman* and Shailja Sood
}

\begin{abstract}
Background: Ischemia reperfusion (I/R) is common in various pathological conditions like diabetic complication, rheumatic arthritis, necrotizing vascular occlusive disease and trauma.

Methods: We have evaluated the effect of tacrolimus (1,2 and $3 \mathrm{mg} / \mathrm{kg}$, p.o. for 10 consecutive days) on femoral arterial ischemic reperfusion (I/R) induced neuropathic pain in rats. Behavioral parameters (i.e. hot plate, radiant heat, acetone drop, tail heat hyperalgesia, tail flick and tail cold allodynia tests) were assessed at different time intervals (i.e. 0, $1,4,7,10,13$ and $16^{\text {th }}$ day) and biochemical analysis in serum and tissue samples were also performed along with histopathological studies.

Results: Behavioral pain assessment revealed increase in the paw and tail withdrawal threshold in tacrolimus treated groups against hyperalgesic and allodynic stimuli as compared to the sham control group. We observed a decrease in the serum nitrate and thiobarbituric acid reactive substance (TBARS) levels along with reduction in tissue myeloperoxidase (MPO) and total calcium levels, whereas, rise in tissue reduced glutathione levels in tacrolimus treated groups. However, significant results were obtained in medium and high dose treated group as compared to sham control group. Histopathological study had revealed the increase in the neuronal edema and axonal degeneration in the I/R group whereas, tacrolimus ameliorate these effects.

Conclusion: Our results indicate the anti-oxidative, anti-inflammatory and calcium modulatory actions of tacrolimus. Therefore, it can be used as a therapeutic agent for the treatment of vascular inflammatory related neuropathic pain.
\end{abstract}

\section{Introduction}

Clinically, neuropathic pain is characterized by sensory symptoms, impairment of motor function as well as vasomotor and sudomotor abnormalities that typically show a spreading tendency with a generalized distal distribution [1]. The peripheral mechanism discussed above include immune cell mediated inflammatory process [2,3], autoimmune inflammatory process [4], neurogenic inflammation [3,5] and tissue hypoxia [6]. However, according to central mechanism develops as a consequence of reorganization of somatosensory, somatomotor and autonomic systems in the CNS triggered by a peripheral input [7].

Novel neuropathic pain model has been proposed in complex regional pain syndrome (CRPS) produced by

\footnotetext{
* Correspondence: arunachalammu@gmail.com

1 Rayat institute of pharmacy, Ropar campus, Nawanshahr district, Railmajra, Near Ropar-144533, Punjab, India

Full list of author information is available at the end of the article
}

prolonged hindpaw ischemia and reperfusion in rat [8]. Ischemic-reperfusion event is well documented to induce potent injury in the targeted organs, which were indicated in the myocardial, renal, liver, lung, stomach and neuronal cells [9-11]. Ischemic-reperfusion process leads to change in the microvascular environment which in turn causes neuronal edema, breakdown of blood-nerve barrier, nerve fiber degeneration, neuronal excitation, decreased nerve conduction velocity, membranous lipid peroxidation, accumulation of free radical, alteration of enzymatic reaction, ion fluxes etc $[12,13]$.

This alteration in neuronal blood flow and neuronal function may leads to partial and/or permanent impairment of quality of life in neuropathic patients. Certain pathological conditions are responsible for the development of vasculatic neuropathy such as diabetes mellitus, vascular occlusive diseases, necrotizing vasculitides, 
peripheral arterial disease, trauma etc [14]. Moreover, peripheral vascular changes are common progressive factors for the acute and chronic ischemic neuropathic pain in patients [15].

The pathophysiology of $I / R$ injury include platelet aggregation, immune cell activation, free radical generation and leukocyte-endothelial cell interactions which lead to the injury of the endothelium and obstruction of capillaries, thus impairing oxygen supply to the nerve tissue [16]. Tacrolimus (FK506) is a potent immunosuppressive drug that has been widely used for organ transplantation and atopic dermatitis. Recently, clinical studies have demonstrated the beneficial effects of this agent in the treatment of various autoimmune and inflammatory diseases such as, rheumatoid arthritis and inflammatory bowel diseases [17]. Tacrolimus has also been reported to possess ameliorative role in the peptic ulcer due to its antioxidant and immunosuppressive action [18]. Therefore, the present study was designed to investigate the ameliorative effect of FK-506 (tacrolimus) on femoral ischemia-reperfusion injury induced neuropathic pain in rats.

\section{Materials and methods Animal}

Wistar rats of either sex weighing between 180-250 g were used. Animals were procured from Punjab Agriculture University, Department of Animal Sciences, Ludhiana. They were kept at standard laboratory diet, environmental temperature and humidity. A $12 \mathrm{~h}$ natural light and dark cycle was maintained throughout the experimental protocol. The animals had free access to standard laboratory chow and water ad libitum. The experimental protocol was duly approved by Institutional Animal Ethics Committee (IAEC) and care of the animals was carried out as per the guidelines of Committee for the Purpose of Control and Supervision of Experiments on Animals (CPCSEA), Ministry of Environment and Forest, Government of India (Reg No:- 874/ac/05/CPCSEA).

\section{Chemicals}

DTNB (5,5'-dithio bis (2-nitrobenzoic acid), BSA (Bovine Serum Albumin), (GSH) reduced glutathione were purchased from Sisco Research Laboratories, Mumbai. Thiobarbituric acid was purchased from Loba Chemie, Mumbai. All other reagents were obtained from S.D. Fine Chemicals, Mumbai, India.

\section{Surgical procedure}

Rats were anesthetizsed intraperitoneally with ketamine $\mathrm{HCl}(50 \mathrm{mg} / \mathrm{kg})$ and xylazine $(5 \mathrm{mg} / \mathrm{kg})$. Animals were then placed in supine position on a heated mat during the operation and recovery. Right femoral vessels were exposed through an inguinal incision and were dissected free from the femoral nerve under operating microscope. Near the trifurcation of the sciatic nerve (into peroneal, tibial and sural branches) ischemia was developed for three hours by occluding the femoral artery with a silk suture (6-0) using slipknot technique [19] and later on reperfusion was achieved by the removal of this ligature. Venous and femoral nerve occlusion was carefully avoided. To prevent thrombosis of the artery, two subcutaneous injections of heparin (8 IU, Roche in $0.3 \mathrm{ml}$ saline) were given, one at the beginning and one at the end of the period of ischemia. In all the groups, silk suture was removed after $3 \mathrm{~h}$ ischemic event to allow reperfusion up to 21 days study protocol. Blood flow was checked under a microscope at the distal site of ligature after removing the silk thread. The animals were placed under heating lamps until they recovered from anesthesia.

\section{Behavioral Study}

Hot plate test Thermal nociceptive threshold, as an index of thermal-hyperalgesia, was assessed by the hot plate test as described by Andreas and Rainer [20]. Eddy's hot plate was pre-heated and maintained at temperature of $52.5 \pm 0.5^{\circ} \mathrm{C}$. Rats were placed on the hot plate and nociceptive threshold was assessed with respect to hind paw licking. Response was recorded in seconds. Cut-off time of $20 \mathrm{~s}$ was maintained.

Plantar test Radiant heat sensitivity of right hind paw was measured under the radiant heat lamp source as described by Hargreaves et al., [21]. The intensity of the radiant heat stimulus was maintained at $25 \pm 0.1^{\circ} \mathrm{C}$. Response of paw withdrawal latency was noted in seconds. Cut-off time of $15 \mathrm{~s}$ was maintained.

Acetone drop test Thermal (non-noxious cold) nonnociceptive threshold, as an index of cold allodynia, was assessed by using acetone drop method as described by Choi et al., [22]. The reactivity to non-noxious cold chemical stimuli was assessed. Rat was placed on the top of the wire mesh grid, allowing access to the hind paws. Acetone $(100 \mu \mathrm{l})$ was sprayed on the plantar surface of the hind paw of rat and time taken to appear the cold sensitive reaction with respect to either paw licking, shaking or rubbing the hind paw was recorded within 20 seconds. Tail heat hyperalgesia test Spinal thermal sensitivity was assessed by the tail immersion test as described by Necker and Hellon [23]. Tail heat-hyperalgesia was noted with the immersion of terminal part of the tail $(1 \mathrm{~cm})$ in water, temperature was maintained at $52.5 \pm 0.5^{\circ} \mathrm{C}$. Duration of the tail withdrawal reflex was recorded, as a response of spinal heat sensation and a cut-off time of 15 s was maintained.

Tail flick test Spinal thermal sensitivity was assessed by the tail flick test as described by D'Amour and Smith [24]. Temperature of heating element (nichrome wire) of anal- 
gesiometer was maintained at $52 \pm 0.5^{\circ} \mathrm{C}$. The tail of rat was placed on analgesiometer at uniform distance from the nichrome wire. The tail flick response was noted and cut-off time of $15 \mathrm{~s}$ was maintained.

Tail cold allodynia test Spinal thermal sensitivity was assessed by the tail immersion test as described by Necker and Hellon [23]. Briefly, the terminal part of the tail $(1 \mathrm{~cm})$ of the rat was immersed in cold non-noxious temperature $\left(8 \pm 0.5^{\circ} \mathrm{C}\right)$, until the tail was withdrawn. The duration of the tail withdrawal reflex was recorded and a cut-off time of $20 \mathrm{~s}$ was used.

\section{Biochemical study}

Blood samples were collected by retro-orbital sinus puncture at different day's interval (i.e., day $0,4,8,12$, and $16^{\text {th }}$. Serum samples were prepared for the evaluation of oxidative stress marker (nitrate and TBARS) changes in rats. Further, tissue samples were employed to estimate reduced glutathione, total calcium, MPO and histopathological evaluation.

Estimation of serum nitrate level The oxidized end product of NO i.e. nitrate was measured in serum samples using a procedure based on the Griess reaction [25]. Potassium nitrate $(80 \mathrm{mM})$ was used as a standard for the determination of nitrate. Serum nitrate levels were expressed as $\mu \mathrm{mol} / \mathrm{L}$.

\section{Estimation of lipid peroxidation (TBARS) Serum}

malondialdahyde (MDA) level, an index of lipid peroxidation, was determined by thiobarbituric acid (TBA) reaction. The principle of the method depends on measurement of the pink color produced by interaction of barbituric acid with malondialdahyde. 1,1,3,3-tetraethoxypropane was used as a primary standard. The determination of MDA level was performed by the method of Yagi [26]. Serum MDA levels were expressed as $\mathrm{nmol} / \mathrm{ml}$.

Estimation of total protein content Protein concentration was estimated according to the method of Lowry et al., [27] using bovine serum albumin as a standard. The absorbance was determined spectrophotometrically at $750 \mathrm{~nm}$.

Estimation of reduced glutathione Reduced glutathione levels were estimated according to the method of Ellman [28]. Equal quantity of tissue homogenate was mixed with $10 \%$ trichloroacetic acid and centrifuged to separate out protein. To $0.01 \mathrm{ml}$ of this supernatant, $2 \mathrm{ml}$ of phosphate buffer ( $\mathrm{pH} 8.4), 0.5 \mathrm{ml}$ of 5,5'-dithio, bis(2nitrobenzoic acid) and $0.4 \mathrm{ml}$ of double distilled water was added. Mixture was vortexed and the absorbance was taken at $412 \mathrm{~nm}$ within $15 \mathrm{~min}$. The concentration of reduced glutathione was expressed as $\mu \mathrm{mol} / \mathrm{g}$ of protein.

Estimation of total calcium Total calcium levels were estimated in the sciatic nerve as described by Severnghaus and Ferrebee [29] and Muthuraman et al., [12].
Briefly, the sciatic nerve homogenate was mixed with 1 $\mathrm{mL}$ of trichloroacetic acid (4\%) in the ice-cold condition and centrifuged at $1500 \times g$ for $10 \mathrm{~min}$. The clear supernatant was used for estimating the total calcium levels by atomic emission spectroscopy at $556 \mathrm{~nm}$.

Estimation of myeloperoxidase activity $\mathrm{MPO}$ an enzyme liberated due to activation of polymorphonuclear leukocytes, is used as an indication of tissue neutrophil accumulation. MPO activity was measured using a procedure similar to that documented by Hillegass et al., [30]. Sciatic nerve tissues were homogenized in $50 \mathrm{mM}$ potassium phosphate buffer ( $\mathrm{pH} 6.0)$, and centrifuged at 2500 rpm (10 min); pellets were resuspended in $50 \mathrm{mM}$ phosphate buffer containing $0.5 \%$ hexadecyltrimethylammoniumbromide (HETAB). After three freeze and thaw cycles, with sonication between cycles, the samples were centrifuged at $2500 \mathrm{rpm}$ for $10 \mathrm{~min}$. Aliquots $(0.3 \mathrm{ml})$ were added to $2.3 \mathrm{ml}$ of reaction mixture containing 50 $\mathrm{mM}$ phosphate buffer, o-dianisidine, and $20 \mathrm{mmol} \mathrm{H}_{2} \mathrm{O}_{2}$ solution. The presence of MPO was measured at $460 \mathrm{~nm}$ for 3 minutes. MPO activity was expressed as $U$ per g tissue. One unit of MPO activity was defined as that degrading $1 \mu \mathrm{mol}$ peroxide per min at $25^{\circ} \mathrm{C}$.

\section{Histopathological study}

Assessment of axonal degeneration Samples of sciatic nerve were stored in the fixative solution ( $10 \%$ formalin) and cut into $4 \mu \mathrm{m}$ thickness size. Staining was done by using hematoxylin and eosin as described by Yukari et al., [31]. Nerve sections were analyzed qualitatively under light microscope $(450 \times)$ for axonal degeneration.

Experimental Design Seven groups were employed in the present study, each consist of six Wistar rats.

\section{Group I (Normal control group)}

Rats were not subjected to any surgical procedure and were kept for 21 days. Behavioral tests were employed to assess nociceptive threshold on day $0,1,4,7,10,13$ and $16^{\text {st }}$ whereas, biochemical analysis was performed for the estimation of serum nitrate and TBARS on day i.e., day 0 , $4,8,12$, and 16 , all animals were sacrificed by cervical dislocation and sciatic nerve tissues were immediately isolated for the study of biochemical (reduced glutathione, total calcium and MPO) and histopathological changes.

\section{Group II - Sham control group}

Rats were subjected to surgical procedure to expose right femoral artery without any vascular damage and ischemia. Behavioral and biochemical tests were employed on different days as described in group I.

\section{Group III - Ischemia-reperfusion control group [I/R]}

Rats were subjected to surgical procedure to expose and develop $3 \mathrm{~h}$ ischemia followed by prolong reperfusion on 


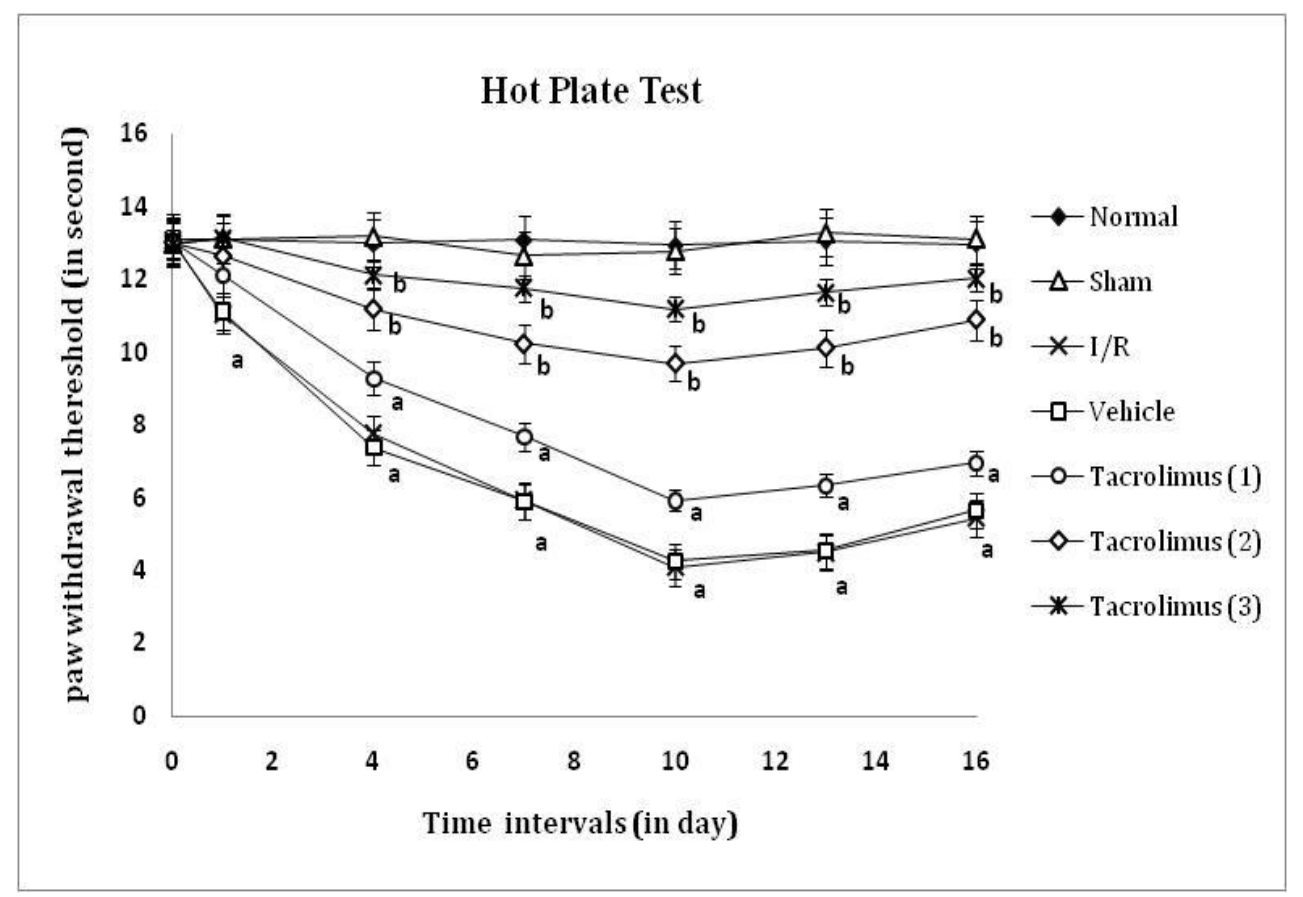

Figure 1 Time course of paw thermal hyperalgesia was measured against noxious conduct heat evoked hind paw licking response. Data were expressed as mean \pm S.E.M., $\mathrm{n}=6$ rats per group. $\mathbf{a}=p<0.05 \mathrm{vs}$ sham control group, $\mathbf{b}=p<0.05 \mathrm{vs} \mathrm{I} / \mathrm{R}$ control group.

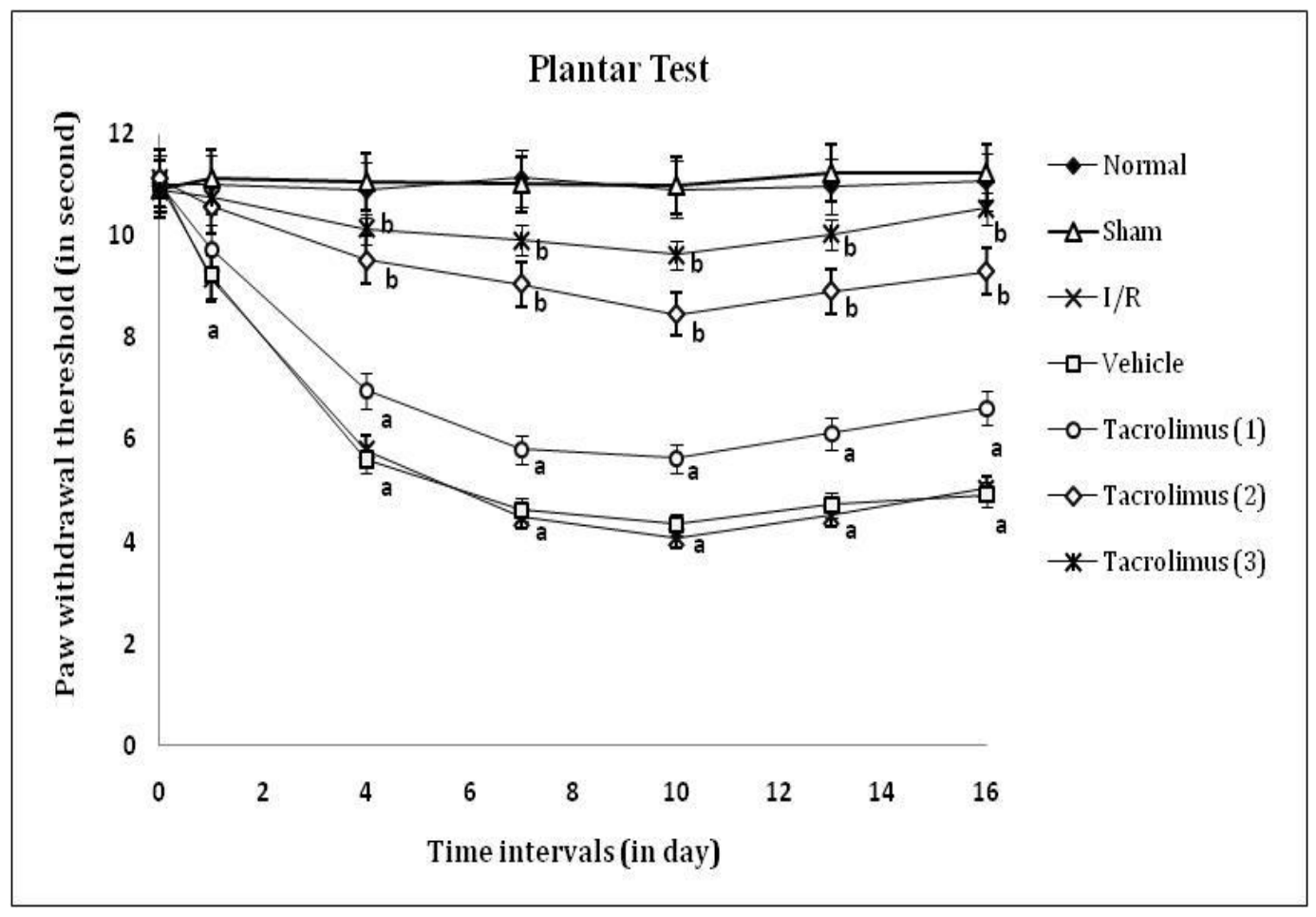

Figure 2 Time course of peripheral thermal hyperalgesia was measured against noxious radiant heat evoked ipsilateral right hind paw withdrawal response. Data were expressed as mean \pm S.E.M., $\mathrm{n}=6$ rats per group. $\mathbf{a}=p<0.05 \mathrm{vs}$ sham control group, $\mathbf{b}=p<0.05 \mathrm{vs} \mathrm{I} / \mathrm{R}$ control group. 


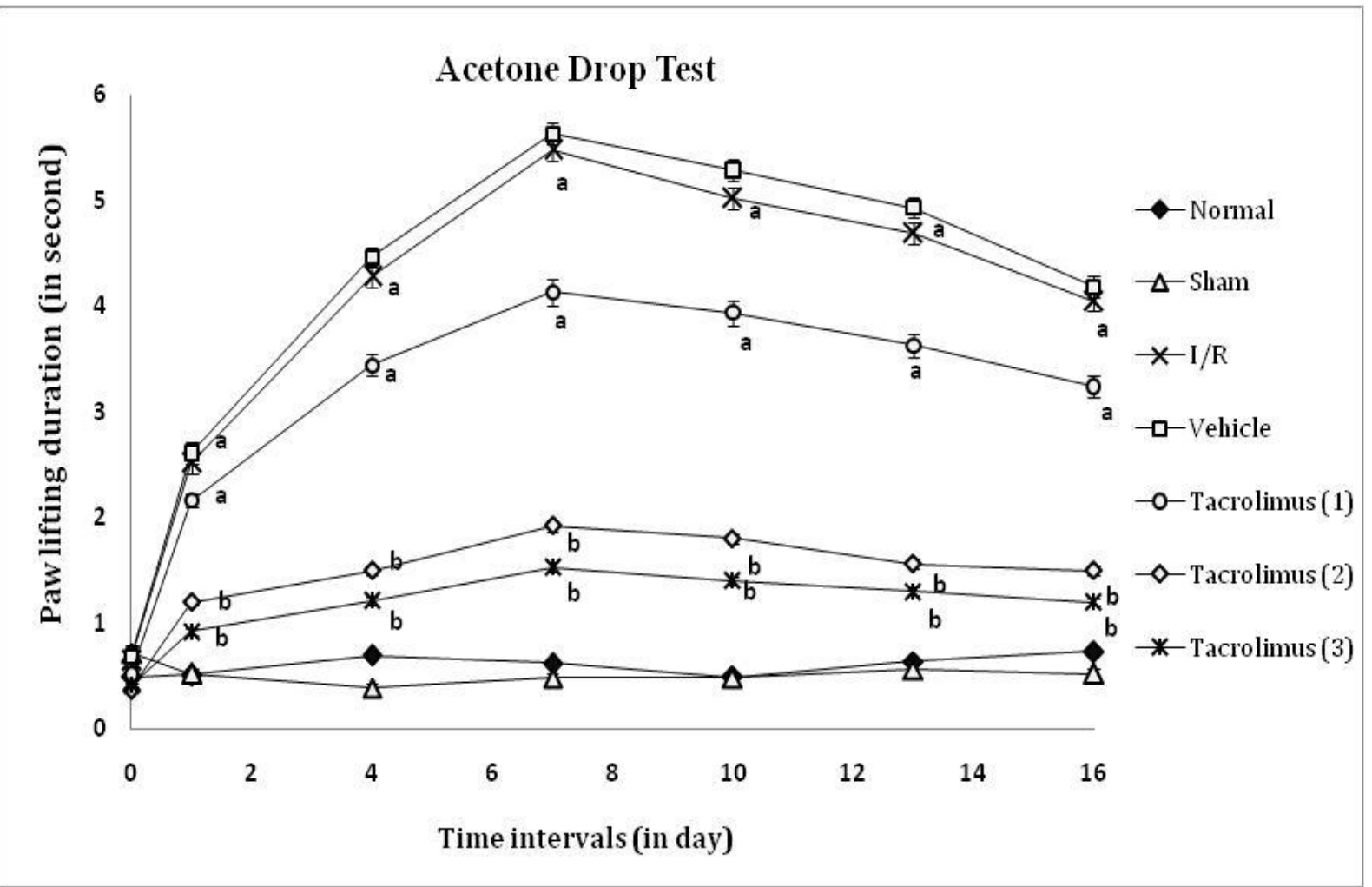

Figure 3 Time course of paw cold allodynia was measured against non-noxious chemical cold evoked paw withdrawal response. Data were expressed as mean \pm S.E.M., $\mathbf{n}=6$ rats per group. $\mathbf{a}=p<0.05$ vs sham control group, $\mathbf{b}=p<0.05 \mathrm{vs} \mathrm{l} / \mathrm{R}$ control group.

right femoral artery. Behavioral tests and biochemical parameters were assessed as described in group I.

\section{Group IV - Vehicle treated group [I/R + Vehicle]}

Vehicle (1\% CMC p.o.) was administered to all the rats upto the end of the study protocol. Behavioral tests and biochemical parameters were assessed as described in group I.

Group V to VII - FK-506 treated group [I/R + FK$506(1,2$ and $3 \mathrm{mg} / \mathrm{kg})$ ]

FK-506 (1, 2 and $3 \mathrm{mg} / \mathrm{kg}$, p.o.) doses were administered in group V to VII respectively upto the end of the study protocol. Behavioral tests and biochemical parameters were assessed as described in group I.

Statistical Analysis All the results were expressed as mean \pm standard error of means (S.E.M). Data obtained from behavioral and serum biochemical tests were statistically analyzed using two-way analysis of variance (ANOVA). The data of tissue biomarker total calcium and MPO were analyzed using one way analysis of variance (ANOVA). In both cases, Tukey's multiple range tests were applied for post-hoc analysis by using Graph pad prism Version-5.0 software. A probability value of $p<$ 0.05 was considered to be statistically significant.

\section{Results}

\section{Behavioral study}

Peripheral thermal (conduction, radiant and chemical) sensitivity was assessed by paw withdrawal threshold and paw lifting duration, as an index of heat hyperalgesia and chemical allodynia by using hot plate, radiant heat lamp and acetone applicator respectively as shown in figure 1, 2 and 3. I/R of femoral artery showed significant decrease in paw withdrawal threshold and increase in paw lifting duration at different days with maximum effect shown at $7^{\text {th }}$ day as compared to sham control group. Whereas, tacrolimus treated groups V to VII showed increase in paw withdrawal threshold and decrease in paw lifting duration but significant results were observed only in the medium and high dose ( 2 and $3 \mathrm{mg} / \mathrm{kg}$, p.o.) treated groups as compared to I/R control group.

Spinal thermal (conduction and radiant) and cold sensitivity were assessed by tail withdrawal latency, as an index of heat hyperalgesia and cold allodynia by using hot water $\left(52 \pm 0.5^{\circ} \mathrm{C}\right)$, analgesiometer and cold water $\left(8 \pm 0.5^{\circ} \mathrm{C}\right)$ respectively as shown in figure 4,5 and $6 . \mathrm{I} / \mathrm{R}$ of femoral artery showed significant decrease in tail withdrawal latency at different days with maximum effect shown at $7^{\text {th }}$ day as compared to sham control group. Whereas, tac- 


\section{Tail Heat Hyperalgesia Test}

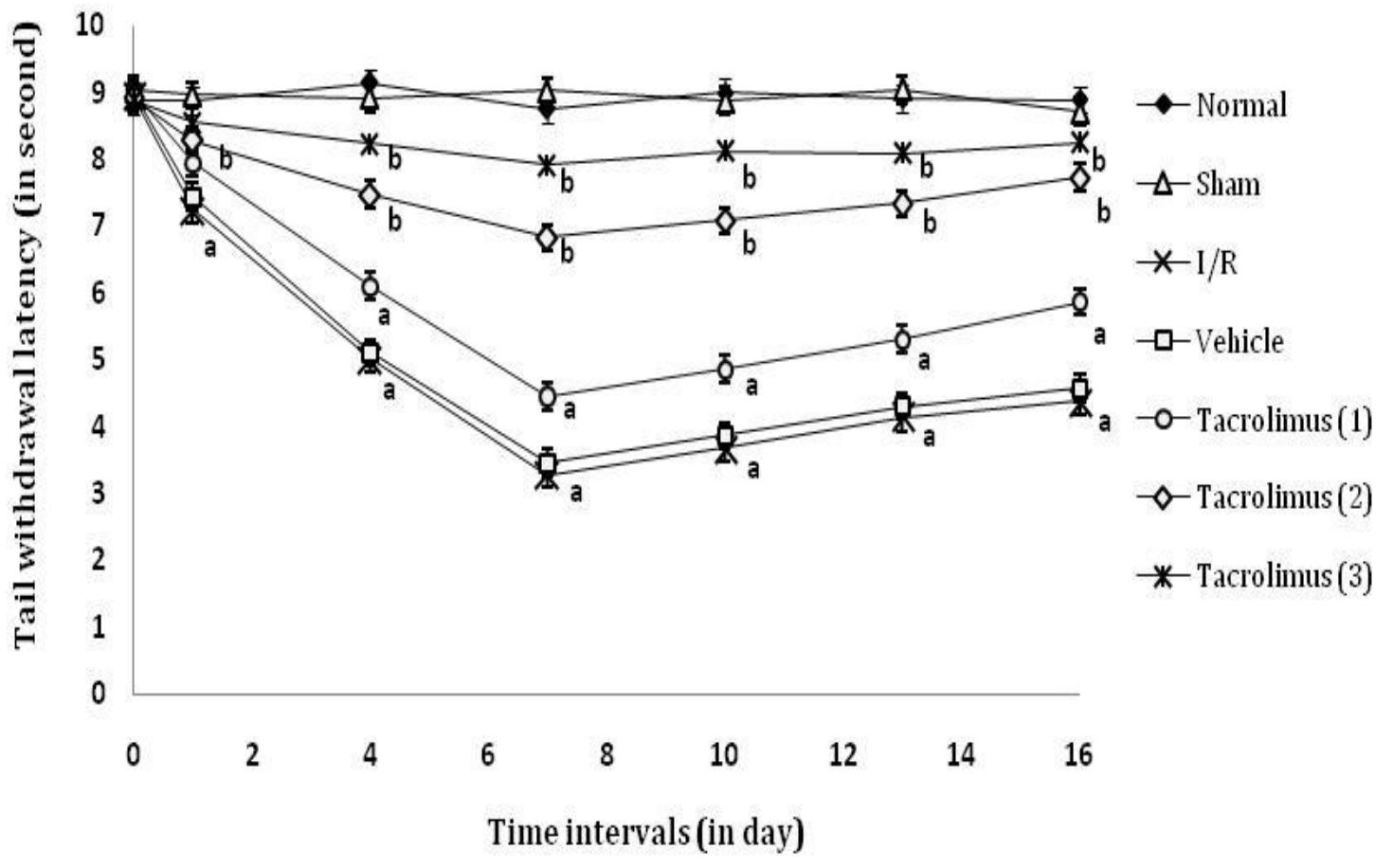

Figure 4 Time course of tail thermal hyperalgesia was measured against noxious warm water immersion evoked tail withdrawal response Data were expressed as mean \pm S.E.M., $\mathrm{n}=6$ rats per group. $\mathbf{a}=p<0.05 \mathrm{vs} \mathrm{sham} \mathrm{control} \mathrm{group,} \mathbf{b}=p<0.05 \mathrm{vs} \mathrm{I/R} \mathrm{control} \mathrm{group.}$

rolimus treated groups V to VII showed increase in tail withdrawal latency but significant results were observed only in the medium and high dose ( 2 and $3 \mathrm{mg} / \mathrm{kg}$, p.o.) treated groups as compared to I/R control group.

\section{Biochemical study}

I/R control group had shown increase in serum nitrate and TBARS levels as compared to sham control group at different day's interval. Further, sciatic nerve tissue samples also showed significant changes in biochemical parameters i.e. increased total calcium level and MPO activity but decreased reduced glutathione level as compared to sham control group. However, tacrolimus treated groups V to VII showed ameliorative effect on serum and tissue biomarker changes but significant results were observed only in the medium and high dose ( 2 and $3 \mathrm{mg} / \mathrm{kg}$, p.o.) treated groups as compared to I/R control group (Table 1 and 2).

\section{Histopathological study}

I/R injury of femoral artery resulted in significant histopathological changes which were assessed in cross sectional section of distal part of sciatic nerve. In cross section, axonal degeneration was shown by decrease in number of myelinated fibers along with swelling of nonmyelinated and myelinated nerve fibers. But tacrolimus treatment ( 2 and $3 \mathrm{mg} / \mathrm{kg}$ ) resulted in attenuation of $\mathrm{I} / \mathrm{R}$ induced axonal degeneration and histopathological alterations (Fig. 7).

\section{Discussion}

In the present study, tacrolimus showed significant amelioration of ischemia reperfusion induced behavioral, biochemical and histopathological changes. Literature revealed that ischemia followed by reperfusion can cause severe damage in heart, intestine, kidney, stomach, brain and peripheral nerve [32]. Ischemic insult of vascular and nervous system in vascular occlusive diseases, necrotiz- 


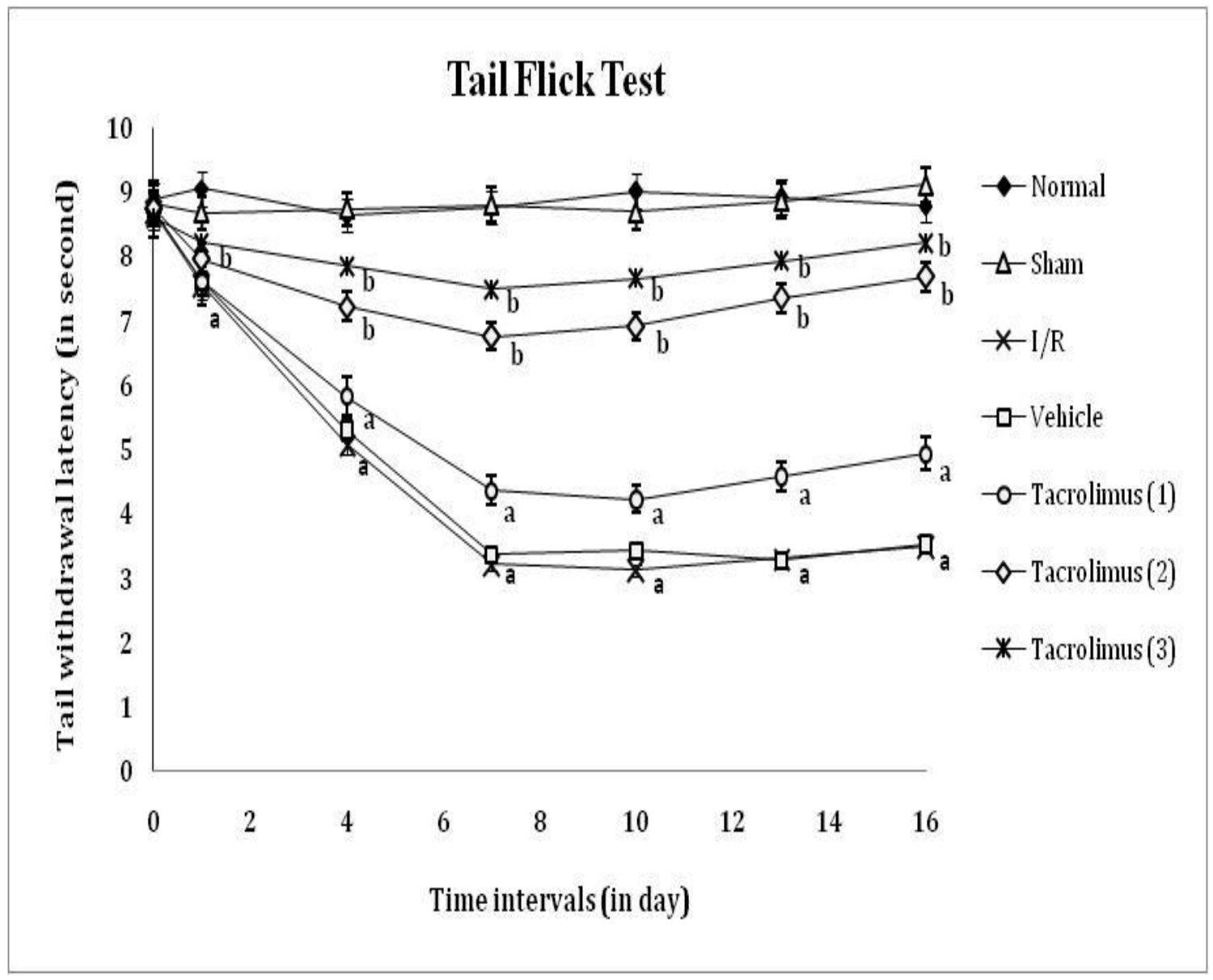

Figure 5 Time course of tail thermal hyperalgesia was measured against noxious radiant heat evoked tail withdrawal response. Data were expressed as mean \pm S.E.M., $\mathbf{n}=6$ rats per group. $\mathbf{a}=p<0.05$ vs sham control group, $\mathbf{b}=p<0.05 \mathrm{vs} \mathrm{l} / \mathrm{R}$ control group.

ing vasculitides, diabetes mellitus and trauma plays a major key role in the development of ischemic pain, vasculatic neuropathic pain etc [33,14]. Severe ischemic insult in nerve has resulted in the energy shutdown followed by conduction failure and fiber degeneration [19]. The most important hypothesis explains that the neuronal cellular reperfusion induced damage is caused by enhancement of the free radical generation, lipid peroxidation, calcium overload, alteration in the level of nitrite/ nitrate, pro/anti-inflammatory cytokines and neuronal apoptotic components, endoneurial edema and augmentation of fiber degeneration [34]. Both ischemic insult and reperfusion process can alter the structural and functional action of the certain targeted cells. In the present study the peripheral nerve has been targeted for induction of vasculatic neuropathy in rats by the process of femoral artery I/R. The event of femoral artery I/R process has been well documented for the induction of the neuro-inflammation, neuronal excitability and enhancement of pain sensation [35].

The production of reactive oxygen species and reactive nitrogen species (ROS/RNS) in severe oxidative stress conditions such as sepsis, trauma, surgery, ischemia, hypoxia and ischemia-reperfusion lead to the loss of membrane integrity and structural or functional changes [36]. Further, generation of free radicals can cause neuronal and endothelial damage through the induction of lipid peroxidation, protein oxidation and direct damage to nucleic acids [37]. Nitric oxide (NO) is an important endogenous vasodilator in the vascular system and plays a protective role in the cardiovascular and other vital organ system. In contrast, it has been suggested that the neuronal blood flow is maintained at low concentration of $\mathrm{NO}$ and the excessive release of $\mathrm{NO}$ may be toxic to the nerve cells [38]. This toxicity may be exacerbated during ischemia and reperfusion due to generation of $\mathrm{O}_{2}$ leading 


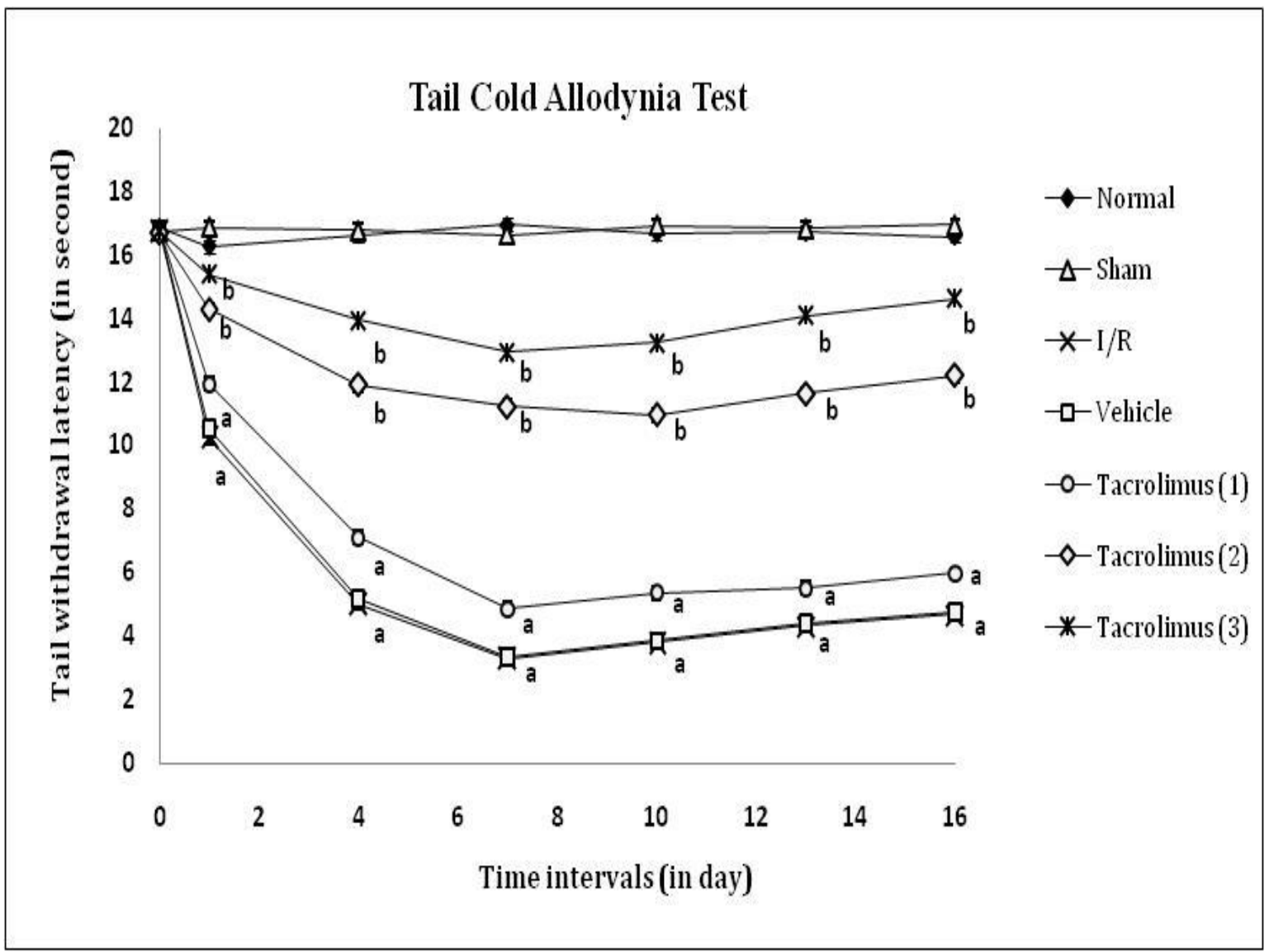

Figure 6 Time course of tail thermal allodynia was measured against non-noxious cold water immesion evoked tail withdrawal response. Data were expressed as mean \pm S.E.M., $\mathrm{n}=6$ rats per group. $\mathbf{a}=p<0.05 \mathrm{vs}$ sham control group, $\mathbf{b}=p<0.05 \mathrm{vs} \mathrm{l} / \mathrm{R}$ control group.

to formation of the peroxynitrite radicals [39]. In the present study, the effect of $\mathrm{I} / \mathrm{R}$ induced behavioral changes were assessed by the hot plate, plantar, acetone drop, tail (heat and cold water) immersion and tail flick tests. Further, neuro-vascular changes were evaluated by direct measurement of the level of nitrate and TBARS in serum and tissue reduced glutathione, total calcium and MPO activity. Results obtained had confirmed I/R injury induced vasculatic neuropathy in rats. However, tacrolimus treatment had resulted in the reduction of such neuropathic pain along with ameliorative effect on biochemical parameters and such $I / R$ induced vasculatic neuropathy clinically resemble to diabetic, rheumatoid vasculatitis, vascular inflammatory and demyelinating related neuropathy [40].

Ischemia reperfusion induced vasculitic neuropathy has shown compelling evidence for the role of myeloperoxidase due to mast cell activation. The pathogenesis of vasculitis is complex and is the result of various autoim- mune reactions, both humoral and cell mediated. There are multiple triggering events or antigens leading to various immunological and histological responses [41]. Moreover, free radicals are also found to be involved in chronic constriction injury, tibial sural transection, axotomy, traumatic injury and peripheral ischemia reperfusion induced neuropathic pain $[6,12,13]$. Peripheral ischemia is recognized as a secondary phenomenon in patients with peripheral arterial disease, vasculatic neuropathy etc. Obstruction of the peripheral arteries of the legs develop peripheral nerve dysfunctions including peripheral ischemic pain in the lower limbs which may be due to the free radicals generation, immune cell activation, calpain activation etc [42].

It is well known that tacrolimus (FK-506) inhibit the induction of iNOS by suppressing the activation of nuclear factor kappa-B (NF-kB) [43]. Recently, it has also been reported that the anti-oxidative, anti-inflammatory and calcium modulatory actions of tacrolimus prevented 
Table 1: Effect of tacrolimus on I/R induced changes in serum nitrate and MDA level

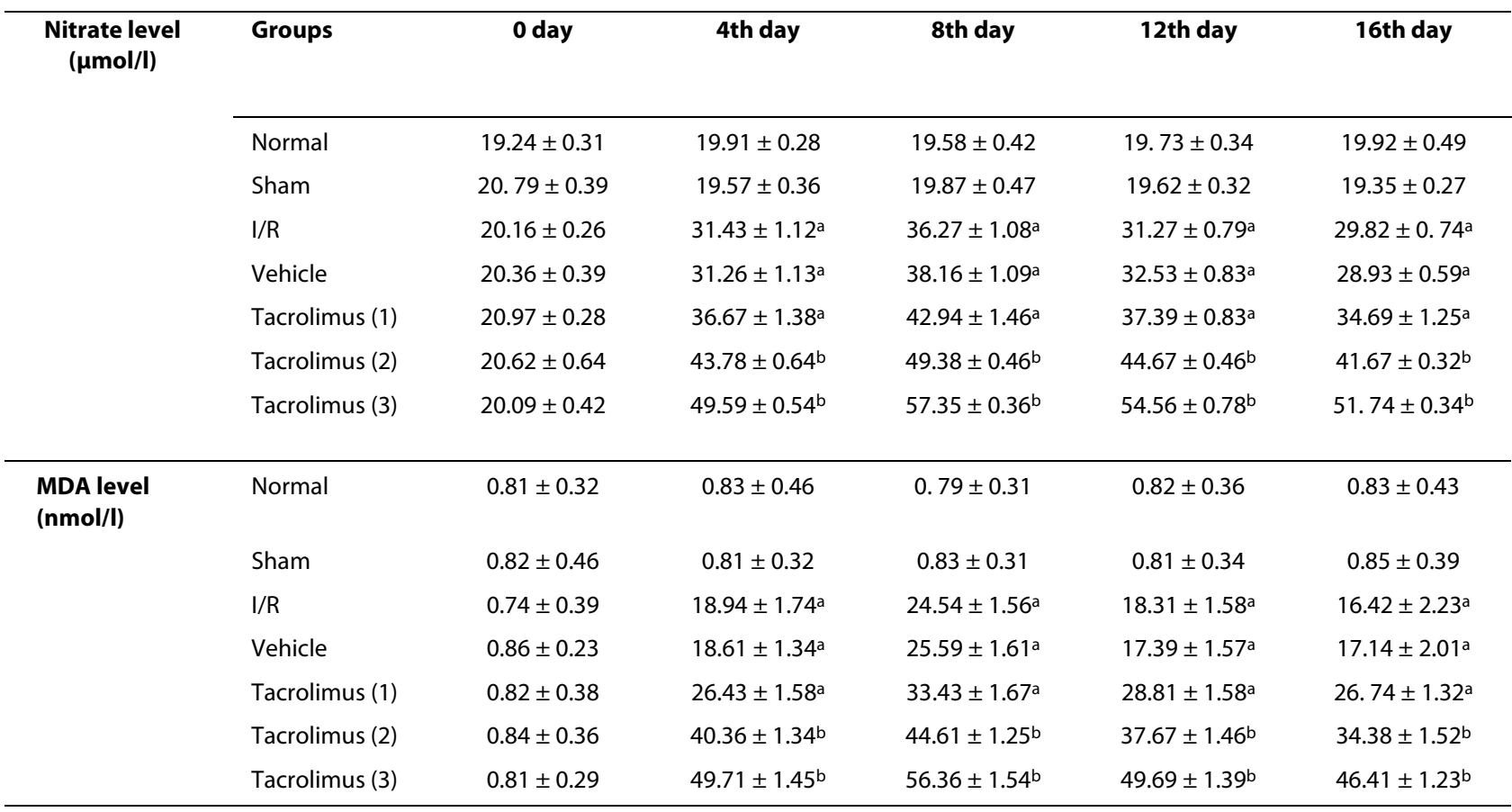

Data were expressed as mean \pm S.E.M. for each group. $\mathbf{a}=P<0.05$ vs sham control group, $\mathbf{b}=P<0.05$ vs ischemia control group.

gastric mucosal lesions [18]. Results revealed that tacrolimus reduce serum nitrate and TBARS levels along with reduction in the tissue total calcium and MPO activity but it showed increase in tissue reduced gluthathion levels. Therefore, from the above discussion it may be concluded that these ameliorative effects on various biomarkers may be due to its effect on decrease in free radical accumulation and inflammatory markers as well as its calcium modulatory actions $[18,44]$.

Histopathological evaluation had also revealed $I / R$ induced axonal degeneration. In fact in $I / R$ induced axonal degeneration, calcium influx has been considered as one of the early events following axon injury that sig- nals the resealing of the severed end by a vesicle mediated process. Calcium induced activation of calpains has been reported in the axonal degeneration $[12,13]$. Calcium induced activation of calpain is also associated with generation of reactive oxygen species from mitochondria [45]. Therefore, tacrolimus prevented the axonal degeneration may be due to its calcenurin inhibitor activity.

\section{Conclusion}

Hence, it may be concluded that tacrolimus may act as potential agent for the amelioration of ischemia reperfusion induced neuropathic pain (complex regional pain

Table 2: Effect of tacrolimus on I/R induced changes in tissue biomarker level

\begin{tabular}{lll}
\hline Groups & $\begin{array}{c}\text { Reduced Glutathione }(\boldsymbol{\mu g} / \\
\text { mg of protein) }\end{array}$ & $\begin{array}{c}\text { MPO Activity } \\
(\mathbf{U} / \mathbf{m i n} / \mathbf{m g} \text { of protein) }\end{array}$ \\
\hline Normal & $72.64 \pm 2.91$ & $11.32 \pm 1.56$ \\
Sham & $71.31 \pm 2.47$ & $12.64 \pm 1.37$ \\
I/Rpm/mg of protein) & $39.25 \pm 1.67^{\mathrm{a}}$ & $134.01 \pm 3.91^{\mathrm{a}}$ \\
Vehicle & $40.54 \pm 1.92^{\mathrm{a}}$ & $138.43 \pm 3.51^{\mathrm{a}}$ \\
Tacrolimus (1) & $46.47 \pm 2.65^{\mathrm{a}}$ & $126.32 \pm 1.47^{\mathrm{a}}$ \\
Tacrolimus (2) & $63.35 \pm 1.69^{\mathrm{b}}$ & $62.79 \pm 2.63^{\mathrm{b}}$ \\
Tacrolimus (3) & $68.41 \pm 1.83^{\mathrm{b}}$ & $34.61 \pm 1.93^{\mathrm{a}}$ \\
\hline
\end{tabular}

Data were expressed as mean \pm S.E.M. for each group.

$\mathbf{a}=P<0.05$ vs sham control group,

$\mathbf{b}=P<0.05$ vs ischemia control group. 


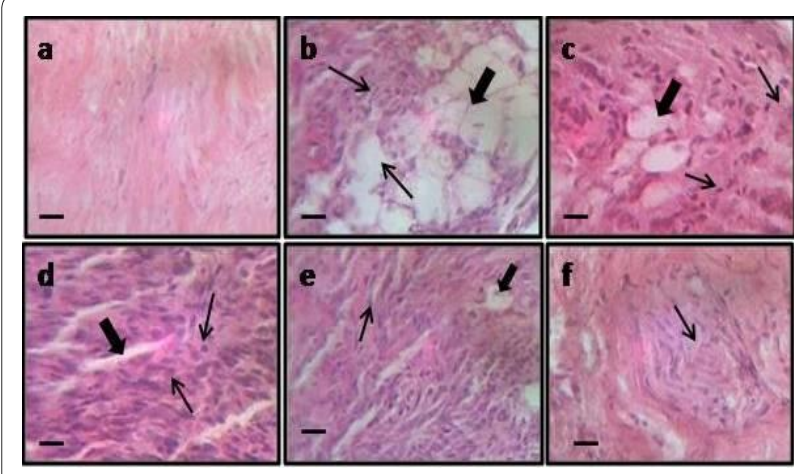

Figure 7 Effect of femoral artery I/R induced neuronal histopathological changes shown in figure a to $f$ (sham, ischemia control, vehicle, tacrolimus (1), tacrolimus (2) and tacrolimus (3) respectively). Fig. b shows neuronal edema and degeneration as compared to sham control group. Moreover, fig e and f shows amelioration of tacrolimus ( 2 and $3 \mathrm{mg} / \mathrm{kg}$ ) on neuronal edema and degeneration in sciatic nerve of rat. Microscopic examinations were performed under $450 \times$ light microcopy, scale bar $10 \mu \mathrm{m}$.

syndrome) due to its antioxidant, calpain inactivation and immunosuppressive actions.

\section{Competing interests}

The authors declare that they have no competing interests.

\section{Authors' contributions}

AM and SS performed experiment procedure, surgery and evaluation of behavioral, biochemical and histopathological study. The authors read and approved the final manuscript.

\section{Acknowledgements}

Thanks to all faculty members of Rayat Institute of Pharmacy for their encouragement and support. We are also grateful to Rayat \& Bahra Educational and Research Trust for their unconditional help to carry out this project.

\section{Author Details}

Rayat institute of pharmacy, Ropar campus, Nawanshahr district, Railmajra, Near Ropar-144533, Punjab, India

Received: 29 October 2009 Accepted: 7 June 2010

Published: 7 June 2010

\section{References}

1. Rommel O, Gehling M, Dertwinkel R, Witscher K, Zenz M, Malin JP, Jänig W: Hemisensory impairment in patients with complex regional pain syndrome. Pain 1999, 80:95-101.

2. Alexander GM, Van Rijn MA, Van Hilten JJ, Perreault MJ, Schwartzman RJ: Changes in cerebrospinal fluid levels of proinflammatory cytokines in CRPS. Pain 2005, 116:213-19.

3. Ludwig J, Baron R: Complex regional pain syndrome: an inflammatory pain condition? Drug Discovery Today: Disease mechanisms 2004, 1:449-55.

4. Goebel A, Vogel H, Caneris O, Bajwa Z, Clover L, Roewer N, Schedel R, Karch H, Sprotte G, Vincent A: Immune responses to campylobacter and serum autoantibodies in patients with complex regional pain syndrome. J Neuroimmunol 2005, 162:184-89.

5. Weber M, Birklein F, Neundorfer B, Schmelz M: Facilitated neurogenic inflammation in complex regional pain syndrome. Pain 2001, 91:251-57.

6. Koban M, Leis S, Schultze-Mosgau S, Birklein F: Tissue hypoxia in complex regional pain syndrome. Pain 2003, 104:149-57.

7. Pleger $B$, Tegentho M, Ragert $P$, Forster AF, Dinse HR, Schwenkreis $P$, Nicolas V, Maier C: Sensorimotor retuning (corrected) in complex regional pain syndrome parallels pain reduction. Ann Neurol 2005, 57:425-29.

8. Coderre TJ, Xanthos DN, Francis L, Bennett GJ: Chronic post ischemia pain (CPIP): a novel animal model of complex regional pain syndrometype I (CRPS-I; reflex sympathetic dystrophy) produced by prolonged hindpaw ischemia and reperfusion in the rat. Pain 2004, 112:94-105.

9. Gong ZX, Ran K, Chang YT, Xu JM: Effect of morphine post conditioning on myocardial ischemia-reperfusion injury in rabbits. Zhejiang Da Xue Xue Bao Yi Xue Ban 2009, 38:521-24.

10. Gupta S, Li S, Abedin MJ, Wang L, Schneider E, Najafian B, Rosenberg ME: Effect of notch activation on the regenerative response to acute renal failure. Am J Physiol Renal Physiol 2010, 298:F209-15.

11. Nouri M, Rahimian R, Fakhfouri G, Rasouli MR, Mohammadi-Rick S, Barzegar-Fallah A, Asadi-Amoli F, Dehpour AR: Ipsilateral common iliac artery plus femoral artery clamping for inducing sciatic nerve ischemia/reperfusion injury in rats: a reliable and simple method. $J$ Brachial Plex Peripher Nerve Inj 2008, 22:27-31.

12. Muthuraman A, Diwan V, Jaggi AS, Singh N, Singh D: Ameliorative effects of Ocimum sanctum in sciatic nerve transection-induced neuropathy in rats. J Ethnopharmacol 2008, 120:56-62.

13. Muthuraman A, Jaggi AS, Singh N, Singh D: Ameliorative effects of amiloride and pralidoxime in chronic constriction injury and vincristine induced painful neuropathy in rats. Eur J Pharmacol 2008, 587:104-11.

14. Kihara M, Schmelzer JD, Kihara Y, Smithson IL, Low PA: Efficacy of limb cooling on the salvage of peripheral nerve from ischemic fiber degeneration. Muscle Nerve 1996, 19:203-09.

15. Iyadurai S, Tsivgoulis G, Sharma VK, Lao AY, Alexandrov AV: Acute painless paraparesis due to bilateral femoral artery occlusion. Eur J Intern Med 2007, 18:553-55.

16. Droge W: Free radicals in the physiological control of cell function. Physiol Rev 2002, 82:47-95.

17. Gewirtz AT, Sitaraman SV: Tacrolimus fujisawa. Curr Opin Investig Drugs 2002, 3:1307-11.

18. Sood S, Muthuraman A: Activity of tacrolimus: An immunosuppressant, in pyloric ligation induced peptic ulcer in rat. Yakugaku Zasshi 2009, 12:1523-28.

19. lida H, Schmelzer JD, Schmeichel AM, Wang Y, Low PA: Peripheral nerve ischemia: reperfusion injury and fiber regeneration. Exp Neurol 2003, 184:997-02.

20. Andreas B, Rainer KWS: Inhibitory avoidance, pain reactivity and plusmaze behavior in wistar rats with high versus low rearing activity. Physiol Behav 2005, 84:387-96.

21. Hargreaves K, Dubner R, Brown F, Flores C, Joris J: A new and sensitive method for measuring thermal nociception in cutaneous hyperalgesia. Pain 1988, 32:77-88.

22. Choi Y, Yoon YW, Na HS, Kim SH, Chung JM: Behavioral signs of ongoing pain and cold allodynia in a rat model of neuropathic pain. Pain 1994, 59:369-76.

23. Necker R, Hellon RF: Noxious thermal input from the rat tail: modulation by descending inhibitory influences. Pain 1978, 4:231-42.

24. D'Amour FE, Smith DL: A method for determining loss of pain sensation. J Pharmacol Exp Ther 1941, 72:74-9.

25. Green LC, Wagner DA, Glogowski J, Skipper PL, Wishnok JS, Tannenbaun SR: Analysis nitrate, nitrite and [15N] nitrate in biological fluids. Anal Biochem 1982, 126:131-8.

26. Yagi K: Simple procedure for specific enzyme of lipid hydroperoxides in serum or plasma. Methods Mol Biol 1998, 108:107-10.

27. Lowry OH, Rosenbrough NJ, Farr AL, Randall RJ: Protein measurement with folin phenol reagent. J Biol Chem 1951, 193:265-75

28. Ellman GL:Tissue sulfhydryl groups. Arch Biochem Biophys 1959, 82:70-7.

29. Severinghaus JW, Ferrebee JW: Calcium determination by flame photometry; methods for serum, urine, and other fluids. J Biol Chem 1950, 187:621-30

30. Hillegass LM, Griswold DE, Brickson B, Albrightson-Winslow C: Assessment of myeloperoxidase activity in whole rat kidney. $J$ Pharmacol Meth 1990, 24:285-95.

31. Yukari S, Sukumar P, Desai AE, Haderer SS, Peter G, Douglas C, Anthony UDG, Ging KW: Neurologic and histopathologic evaluation after highvolume intrathecal amitriptyline. Reg Anesth Pain Med 2004, 29:434-40.

32. Gholami MR, Abolhassani F, Pasbakhsh P, Akbari M, Sobhani A, Eshraghian MR, Kamalian N, Amoli FA, Dehpoor AR, Sohrabi D: The effects of 
simvastatin on ischemia-reperfusion injury of sciatic nerve in adult rats. Eur J Pharmacol 2008, 590:111-14.

33. Kwak KH, Han CG, Lee SH, Jeon Y, Park SS, Kim SO, Baek WY, Hong JG, Lim DG: Reactive oxygen species in rats with chronic post-ischemia pain. Acta Anaesthesiol Scand 2009, 53:648-56.

34. Haendeler J, Hoffmann J, Zeiher AM, Dimmeler S: Antioxidant effects of statins via S-nitrosylation and activation of thioredoxin in endothelial cells: a novel vasculoprotective function of statins. Circulation 2004 110:856-61.

35. Ludwig J, Gorodetskaya N, Schattschneider J, Janig W, Baron R: Behavioral and sensory changes after direct ischemia-reperfusion injury in rats. EurJ Pain 2007, 11:677-84.

36. Gholami MR, Abolhassani F, Pasbakhsh P, Akbari M, Sobhani A, Sohrabi D, Mehrania K: The effects of simvastatin on functional recovery of rat reperfused sciatic nerve. Pak J Biol Sci 2007, 10:4256-60.

37. Honjo M, Tanihara H, Nishijima K, Kiryu J, Honda Y, Yue BY, Sawamura T: Statin inhibits leukocyte-endothelial interaction and prevents neuronal death induced by ischemia-reperfusion injury in the rat retina. Arch Ophthalmol 2002, 120:1707-13.

38. Schmidtko A, Tegeder I, Geisslinger G: No NO, no pain? The role of nitric oxide and CGMP in spinal pain processing. Trends Neurosci 2009, 32:339-46.

39. Martucci C, Trovato AE, Costa B, Borsani E, Franchi S, Magnaghi V, Panera $A E$, Rodella $L F$, Valsecchi $A E$, Sacerdote $P$, Colleoni M: The purinergic antagonist PPADS reduces pain related behaviours and interleukin-1 beta, interleukin-6, iNOS and nNOS overproduction in central and peripheral nervous system after peripheral neuropathy in mice. Pain 2008, 137:81-95

40. Lee J, Shun C, Hsieh S, Hsieh S: Skin denervation in vasculitic neuropathy. Arch Neurol 2005, 62:1570-73

41. Xiao H, Heeringa P, Hu P, Liu Z, Zhao M, Aratani Y, Maeda N, Falk RJ, Jennette JC: Antineutrophil cytoplasmic autoantibodies specific for myeloperoxidase cause glomerulonephritis and vasculitis in mice. J Clin Invest 2002, 110:955-63.

42. Lang PM, Schober GM, Rolke R, Wagner S, Hilge R, Offenbacher M, Treede RD, Hoffmann U, Irnich D: Sensory neuropathy and signs of central sensitization in patients with peripheral arterial disease. Pain 2006, 124:190-200.

43. Kaibori M, Sakitani K, Oda M, Kamiyama Y, Masu Y, Nishizawa M, Ito S, Okumura T: Immunosuppressant FK506 inhibits inducible nitric oxide synthase gene expression at a step of NF-kappa B activation in rat hepatocytes. J Hepatol 1999, 30:1138-45.

44. Fruman DA, Klee CB, Bierer BE, Burakoff SJ: Calcineurin phosphatase activity in Tlymphocytes is inhibited by FK 506 and cyclosporin A. Proc Natl Acad Sci USA 1992, 89:3686-90

45. Carriedo SG, Sensi SL, Yin HZ, Weiss JH: AMPA exposures induce mitochondrial $\mathrm{Ca}(2+)$ overload and $\mathrm{ROS}$ generation in spinal motor neurons in vitro. J Neurosci 2000, 20:240-50.

doi: $10.1186 / 1749-7221-5-13$

Cite this article as: Muthuraman and Sood, Pharmacological evaluation of tacrolimus (FK-506) on ischemia reperfusion induced vasculatic neuropathic pain in rats Journal of Brachial Plexus and Peripheral Nerve Injury 2010, 5:13

\section{Submit your next manuscript to BioMed Central} and take full advantage of:

- Convenient online submission

- Thorough peer review

- No space constraints or color figure charges

- Immediate publication on acceptance

- Inclusion in PubMed, CAS, Scopus and Google Scholar

- Research which is freely available for redistribution

Submit your manuscript at www.biomedcentral.com/submit
C Biomed Central 